\title{
A Systematic Review to Identify Implementation Targets of Mindfulness-Based Interventions for Cardiovascular Risk to Enhance Engagement with Racial/Ethnic Minorities
}

\section{Tonya Faye Sanchez ( $\nabla$ tonya_sanchez@brown.edu )}

Brown University School of Public Health https://orcid.org/0000-0002-4838-0538

\section{E. Karina Santamaria}

Brown University School of Public Health

\section{Dana Rubenstein}

Duke University School of Medicine Judson Brewer

Brown University School of Public Health

Don Operario

Brown University School of Public Health

\section{Research Article}

Keywords:

Posted Date: January 25th, 2022

DOI: https://doi.org/10.21203/rs.3.rs-557519/v2

License: (c) (1) This work is licensed under a Creative Commons Attribution 4.0 International License. Read Full License

Version of Record: A version of this preprint was published at Mindfulness on September 21st, 2022. See the published version at https://doi.org/10.1007/s12671-022-01986-5. 


\section{Abstract}

Cardiovascular disease (CVD) is a persistent public health challenge and racial/ethnic minority populations experience disparities in CVD risk factors. Mindfulness-based Interventions (MBI) have been examined as a strategy to address CVD risk factors, though their potential for implementation with racial and ethnic minorities remains unclear. This review examines primary interventions studies testing the impact of MBI on CVD risk, with a focus on critical appraisal of implementation characteristics (i.e., intervention design, delivery, uptake, and contextual factors) relevant to the engagement of racial/ethnic minority populations. A systematic review identified 30 studies published through January 2022 for inclusion. Included studies were randomized controlled trials testing meditation or mindfulness-based interventions against any control to measure change or improvement in cardiovascular health measures or risk behaviors in adults living in the United States or territories. The Oxford Implementation Index was utilized to identify and extract relevant implementation data, and critical analysis of each study's implementation process was conducted. All identified studies were published between 2011 and 2021 and represent early or pilot stages of research. As such, limitations and barriers in implementation strategies for racial/ethnic minority populations were identified. This review outlines several potential targets for future research to enhance engagement with racial/ethnic minorities.

\section{Introduction}

In the United States (US), cardiovascular disease (CVD) is the leading cause of death among adults (Centers for Disease Control, 2016), with CVD and risk factors disproportionately impacting racial and ethnic minorities (Mensah et al., 2005; Levine et al., 2017; Graham, 2014; Lackland, 2014; Walton-Moss et al., 2014). Factors contributing to these disparities exist at multiple levels from biological to structural (Muncan, 2018; Kurian \& Cardarelli, 2007) and as such, require concerted public health efforts to address fully. This review focuses on mindfulness-based interventions (MBI) as individual-level treatment adjunctives for the primary prevention of CVD in American racial/ethnic minorities. Primary prevention interventions for CVD considered in this review targeted modifiable cardiovascular risk factors and behaviors including: (1) diabetes mellitus (type-2), (2) smoking, (3) obesity, (4) sedentary lifestyle, (5) unhealthy diet (Centers for Disease Control, 2016, Mensah et al., 2005; Levine et al., 2017).

Significant disparities in cardiovascular disease risk in racial and ethnic minorities are well-documented. The National Center for Health Statistics reported that Hispanic and Non-Hispanic Black men are more likely to be obese and to have diabetes, compared with men in other racial/ethnic categories (Davis et al., 2007). Levels of fitness for Black and Mexican Americans are also lower (Graham, 2015; Centers for Disease Control \& Prevention, 2014). Smoking rates are disproportionately high in Native Americans, reaching an estimated $40-50 \%$ in some Native American community populations (Centers for Disease Control \& Prevention, 2014). Black Americans are more likely to die of smoking-related illnesses than White Americans, despite having lower rates of smoking (Kochanek et al., 2014). There are interactions between risk factors as well, with cigarette smoking contributing to a 30-40\% increased risk of diabetes (National Center for Chronic Disease Prevention \& Health Promotion, 2014). Obesity prevalence is also 
disproportionately high in several minority groups, including Black women, Mexican-Americans, Puerto Ricans, and Native Americans (Smith et al., 2005). Inclusive and culturally relevant interventions are necessary to promote equity and reduce disparities in CVD risk factors.

As an emerging individual-level approach to improve mental and physical health outcomes, mindfulness is described as "paying attention in a particular way: on purpose, in the present moment, and nonjudgmentally" (Kabat-Zinn, 2003) and has been operationally defined using a two-component model emphasizing maintenance of attention on a target and nonjudgmental appraisal of experience (Bishop et al., 2006). Mindfulness-Based Interventions (MBI) have their roots in Buddhist practice and were popularized in the United States after the development of Mindfulness-Based Stress Reduction (MBSR), an 8-week long, group-based intervention (Tang et al., 2015). Since that time, the amount of research on $\mathrm{MBI}$ and the underlying mechanisms of mindfulness as a health intervention for various conditions has increased dramatically. Popularly studied MBIs still include MBSR, which incorporates didactic training and body sensing components such as yoga and tasting exercises (i.e. the raisin task) into meditation or mindfulness practice (Kabat-Zinn, 2003). Mechanistically, mindfulness meditation is proposed to act on behavior change targets through enhanced emotional and attentional regulation, increased bodily awareness, and changes in static self-perception (Hölzel et al., 2011; Tang et al., 2015). While MBSR was originally conceived as a treatment option for chronic pain (Kabat-Zinn, 1982), its basic structure has been modified by subsequent researchers to target a wide range of conditions, including CVD risk factors (Loucks et al., 2015a).

Mindfulness practice has been on the rise in the United States. A 2016 study by Cramer et al. (2016) revealed that over 11 million adults reported having practiced meditation at least once in their lives, with over $78 \%$ reporting practice within the last 12 months. Predictors of meditation use included being White, female, college-educated (or higher), and living in the Western United States (Cramer et al., 2016). A subsequent study estimated that $18.6 \%$ of the population ( 46.1 million, or roughly 1 in 5 ) had practiced some form of meditation, and also found that these participants were more likely to be young, female, highly educated, and White (Macinko \& Upchurch, 2019). Populations experiencing health inequities (e.g., due to socioeconomic and structural barriers) are less likely to engage in mindfulness practices in their daily lives (Olano et al., 2015). Moreover, MBI research has also been found to under-enroll non-White participants. In a review of 69 randomized controlled trials of MBIs, $79 \%$ of participants in 56 articles identified as White (Waldron et al., 2018). Another review of 94 trials of MBSR or mindfulness-based cognitive therapy found that $89 \%$ of the total participant population ( $n=4,030$ total) were White (Eichel et al., 2021). Thus, disparities in mindfulness practice might be rooted in underrepresentation of $\mathrm{racial} / \mathrm{ethnic}$ minorities in basic mindfulness research.

Mindfulness-based Interventions (MBI) are increasingly studied for the treatment of CVD and risk factors (Loucks et al., 2015a; Scott-Sheldon et al., 2020). According to a scientific statement from the American Heart Association (Levine et al., 2017), the current literature suggests that MBI are a low-cost, low risk adjunctive treatment for the modification of lifestyle related to cardiovascular risk. Despite the disparate rates of CVD morbidity, mortality, and risk in US racial/ethnic minority populations, the implementation 
potential of these interventions for US racial/ethnic minorities remains largely unexplored. Therefore, we conducted a systematic literature review on MBI interventions for CVD risk outcomes to (i) summarize the stated implementation characteristics of primary studies and (ii) critically appraise these implementation characteristics with regard to facilitators and barriers for engaging racial/ethnic minority populations.

The current review differs from a recently published article by Eichel and colleagues (Eichel et al., 2021) in our focus on MBI study implementation characteristics (i.e., design, delivery, uptake, \& contextual factors) and their relevance as targets for engaging racial and ethnic minorities at risk for cardiovascular disease in the United States.

Evidence suggests that MBIs are a low-cost, feasible, and efficacious treatment option for a range of psychological problems (Chiesa \& Serretti, 2009; Khoury et al., 2013), and further research suggests benefit and acceptability for health disparities. In a qualitative study with a sample of predominantly Black adults seeking mental health treatment, participants conveyed perceived benefits of MBI on physical health conditions, such as diabetes and blood pressure (Spears et al., 2017). Interventions such as $\mathrm{MBI}$ are a tool for wellness which have the potential for use in everyday life including home practice, recordings, smartphone-based apps, and community practice environments. In addition to the benefits these interventions convey, interventions tailored specifically for minority populations can be tailored to bring awareness to population-level stressors and health concerns, raising awareness and creating the potential for dialog around health symptoms and behaviors.

\section{Methods}

The search strategy for this systematic review was guided by specification of the research question parameter, based on $\mathrm{PI}(\mathrm{E}) \mathrm{CO}$ (Table 1). The protocol for this review was developed in consultation with a subject librarian as well as experts in mindfulness-based interventions, public health interventions, and systematic reviews. Database-specific search strategies were created to accommodate truncation and MeSH or Emtree terms. The search was conducted on February 9, 2020, and later updated on January 19, 2022. This protocol was registered with the Prospero International Prospective Register of Systematic Reviews (registration number CRD42019141454) on 09/27/2019. The following five electronic databases were searched: PubMed, EMBASE, PsycINFO, Cochrane Library (CENTRAL) and CINAHL using search strategies outlined in the study protocol (See Appendix 1). Additionally, the electronic database OpenGrey was searched and no eligible studies were discovered. We also conducted forward and backward citation tracking for included studies, key papers, and relevant systematic reviews. Search results and other relevant articles were entered into a web-based systematic review tool designed to facilitate the process of screening, data extraction, and analysis (http://www.covidence.org). 
Table 1

$\mathrm{PI}(\mathrm{E})$ COS Outline.

\begin{tabular}{|ll|}
\hline Population & Healthy or unhealthy adults (18+) residing in the United States or territories. \\
\hline Intervention/Exposure & $\begin{array}{l}\text { Meditation or mindfulness-based intervention with a predetermined } \\
\text { curriculum consisting of at least 1 practice session. }\end{array}$ \\
\hline Control & $\begin{array}{l}\text { Any control group. Active and/or passive control groups. } \\
\text { Outcomes }\end{array}$ \\
$\begin{array}{l}\text { Change or improvement in cardiovascular health measures or risk } \\
\text { behaviors. }\end{array}$ \\
\hline Study Design & Randomized Controlled Trials (RCTs) \\
\hline
\end{tabular}

The primary author performed initial screening of all identified titles and abstracts generated by our search strategy and removed studies which clearly did not meet inclusion criteria (see Table 1). A second author independently screened $10 \%$ of these studies and met at least $80 \%$ agreement between authors. Full-text articles of all selected abstracts were obtained and screened for inclusion. Two authors performed an independent review of articles to determine final eligibility, with differences resolved through a senior author. Finally, a subject expert was consulted prior to the conclusion of this research to verify that included studies were representative of the current literature and appropriate for the study's aims and objectives. The results of this screening are summarized by the PRISMA diagram in Figure 1 .

This review considered randomized controlled trials of meditation or mindfulness-based interventions (as defined by Crane et al., 2016) conducted in the United States and territories with adult participants. Studies were limited to the United States to maintain focus on the unique healthcare considerations and other US-specific racial/ethnic disparities present there. "Mindfulness-informed" therapies (as defined by Crane et al., 2016) where mindfulness or meditation practice were optional or not considered to be the intervention's core component-such as Dialectical Behavioral Therapy (DBT) and Acceptance and Commitment Therapy (ACT) -were excluded. Similarly, studies using psychotherapies such as Cognitive Behavioral Therapy (CBT) were also excluded. Interventions including multivariate components to tailor interventions to health conditions or populations were considered eligible for inclusion if they included a mindfulness-based practice component, even if other components were didactic or did not otherwise center around mindfulness.

With regard to study outcomes, this review included studies of $\mathrm{MBI}$ for the improvement of the following six modifiable risk factors for CVD: (1) diabetes mellitus (type-2), (2) smoking, (3) obesity, (4) sedentary lifestyle, (5) unhealthy diet, (6) blood lipids (high cholesterol). This set of risk factors was chosen due to previous work by Loucks and colleagues, who have proposed a theoretical framework and potential mechanisms for mindfulness on cardiovascular risk (Loucks et al., 2015a; Crane et al., 2016). To qualify for inclusion, studies needed to measure at least one physical or behavioral outcome relating to these risk 
factors (ie: weight, glycemic levels, emotional eating, cigarettes smoked). Primary correlational findings (i.e., longitudinal studies on trait mindfulness) were not included. Studies including secondary health outcomes were eligible for inclusion only if one or more of the above risk factors was examined as a primary outcome.

The Oxford Implementation Index (OIl; Montgomery et al., 2013) is a checklist for reporting implementation data in primary intervention research articles, and was used to guide the extraction and analysis of implementation data from the included studies (see Appendix 1). Five key domains in two categories from the Oll were selected for use in this study based on their relevance to the implementation of MBI: 1) Implementation characteristics: (a) dosage; (b) delivery method; c) staff characteristics; (2) Contextual factors: (d) settings, locations, and dates/times; and (e) participant characteristics. Current existing literature on tailoring interventions to minority populations was consulted and used to further guide our analysis of implementation characteristics extracted from included studies.

\section{Results}

Electronic database searches retrieved 12.163 articles with 9,950 remaining after the removal of duplicates. After screening the title and abstract of each, the full text of 95 articles was retrieved for further review. A total of 30 articles were selected for final inclusion, and the bibliographies of all studies were hand-searched for additional relevant studies. A full breakdown of this search process including reasons for exclusion can be seen in Figure 1, and a list of excluded full-text studies can be found in the Supplementary Table for this article. Of the included studies, the majority examined outcomes related to diet $(n=15)$, smoking $(n=12)$, and obesity $(n=9)$. The remaining studies examined outcomes related to exercise $(n=4)$, diabetes $(n=3)$, and blood lipids $(n=2)$. Numerous studies $(n=11)$ examined more than one risk factor. Number of participants ranged from 18 to 412 with $n=24$ studies having $<100$ participants. All articles included were published between 2011-2021. Papers reporting secondary analyses of MBI interventions on cardiovascular risk outcomes were excluded from this review (see Supplementary Table).

Tables 2 and 3 can be found in the supplemental file section.

Recruitment. Of the 30 studies included in this review, 28 reported some aspect of the recruitment process. Only 1 study reported specific measures taken to tailor recruitment to a racially or ethnically diverse population (Woods-Giscombe \& Gaylord, 2019). Only 3 studies described the language used in recruitment materials, all of which were English only (Davis et al., 2013, Davis et al., 2014b; Ruscio et al., 2017).

Implementation characteristics. Table 3 presents information extracted from primary studies regarding implementation characteristics of the primary studies. Dosage varied widely across studies, with the majority closely modeled after the multi-week, multi-hour model set forth by MBSR and its contemporaries. Program length ranged between 1 day and 6 months, with 27 studies consisting of $\geq 6$ sessions. Session durations ranged between 5 minutes and 7 hours. Dates and times of program delivery 
remained largely undescribed. Thirteen studies reported home practice of between 15-45 minutes for between 5-7 days per week. Delivery method was largely in-person in a group setting $(n=20)$, with 2 delivered in person individually, and 8 delivered remotely or digitally. Staff characteristics-which were at least partially detailed in 17 studies -were universally described in terms of vocation and training, with no descriptive characteristics of the staff/providers described in the primary studies (age, racial/ethnic background). No proscribed/incompatible activities or details of meetings/communication between staff were reported. Numerous studies reported differences between trial arms which did not directly relate to the research question of this review and are therefore not outlined herein.

Contextual factors. Table 3 presents contextual factors that were deemed relevant to this review. Setting, geographic location, and dates/times were at least partially described in 13 studies. Four studies reported school, campus, or laboratory settings (Carpenter et al., 2019; Carmody et al., 2012; Lotfalian et al., 2020; Woods-Giscombe \& Gaylord, 2019) and five reported home or naturalistic settings (Gillman \& Bryan, 2020; Ruscio et al., 2015; Minami et al., 2021; Sala et al., 2020; Wright et al., 2020). The other sixteen studies provided no description of these factors. Participant characteristics were at least partially described in 26 studies (see Table 3). A total of 19 studies reported majority white participants, with 8 reporting mixed race/majority Black or Latinx, and 4 not reporting participant demographics (see Table 2).

Other salient characteristics were partially described (see Table 3). Median age ranged from 20-74 across all studies. Women were disproportionately represented in 18 studies ( $>50 \%$ female), 5 studies reported over $50 \%$ males, and 4 studies had a combination of the two. Gender identity (as differing from biological sex) was not reported in any study, and LGBTQ+ demographics were considered in one study (Ingraham et al., 2017), which consisted of lesbian participants. Educational attainment was reported in 19 studies and revealed that the majority of recruited participants had at least greater than high school education (14 studies). Income was described in 11 studies, seven of which were comprised of participants making $>50 \mathrm{k}$ annually. Three studies specifically focused on low-SES participants (Davis et al., 2014a; Davis et al., 2014b; Vidrine et al., 2016), though two of these studies did not describe income-based inclusion criteria or annual income for participants, instead focusing on low-income neighborhoods during recruitment (Davis et al., 2014a; Davis et al., 2014b).

In nearly all studies, previous interest in, knowledge of, or experience with mindfulness was not controlled for or was not described. One study excluded participants' current or recent (previous 6 months) mindfulness or meditation practice (Chacko et al., 2016), another explicitly excluded participants with prior participation in a mindfulness program (Corsica et al., 2014) and another (Daubenmier et al., 2011) excluded participants with prior MBSR experience or a current meditation or yoga practice. One study explicitly excluded participants if they had any previous formal training in meditation or another form of 
mind-body practice (Woods-Giscombe \& Gaylord, 2019). No studies explicitly screened participants for previous knowledge of or interest in mindfulness or meditation practice, and it was unclear in most studies if recruitment or screening materials mentioned mindfulness or meditation, which may have contributed to self-selection. Two studies (Davis et al., 2014a; Ruscio et al., 2017) mentioned 'mindfulness' or 'meditation' in recruitment materials. One study (Smith et al., 2018) avoided mention of mindfulness in recruitment materials to avoid potential self-selection or the contamination of the control group. One study (Ruscio et al., 2015) lists the mention of mindfulness as a limitation. Two additional studies listed limitations for not excluding based on prior mindfulness experience (Ruscio et al., 2015) or not screening for prior exposure (Smith et al., 2018). Finally, one study (Vidrine et al., 2016) did include subjects with previous experience which they report did not impact findings.

In addition to these factors, it should be noted that the majority of studies were described as being in the early stages of research, either as preliminary research, feasibility studies, and/or pilot trials. This may account for many commonly reported limitations including small sample sizes, convenience sampling, and lack of generalizability. Future research will need to address these limitations, and reasons for attrition should be explored vis-à-vis racial and ethnic background.

\section{Discussion}

While research points to potential benefits of $\mathrm{MBI}$ for cardiovascular risk, this review finds that the current literature may not generalize to or be inclusive of US racial/ethnic minorities who are most disproportionately affected. Our appraisal of implementation characteristics reported in primary MBI trials indicates limitations with regard to inclusion/engagement of diverse populations and consideration of cultural or social factors that might affect program relevance and effectiveness with racial/ethnic minorities. Furthermore, data relevant to understanding implementation factors needed to tailor these interventions to underserved populations are underreported in the current literature. Findings from this review support those recently reported by Eichel and colleagues documenting that racial and ethnic minorities and individuals of low socioeconomic status are underrepresented in the MBI literature (Eichel et al., 2021). Furthermore, our review and critical appraisal found that research on MBI interventions for addressing CVD risk factors is still in the early stages, with the majority of studies showing promising effects on smoking reduction and abstinence, weight loss, and changes in eating behaviors. Considering that the included studies report beneficial findings for cardiovascular risk-which occurs at disparate rates in minorities-the lack of representation presented in these findings presents a clear gap in the literature which should be addressed in future studies. Details on implementation factors (implementation site/provider/delivery factors, contextual factors, participant factors) were unevenly reported in the primary papers. Notably, participant characteristics, staff characteristics, and study settings, locations, times and dates were underreported. No intervention effectiveness or studies otherwise meant to tailor MBI to minorities at risk for CVD have been conducted at this time beyond those reported here, to the best of our knowledge. More consistent and transparent reporting of these 
implementation characteristics is necessary to establish a baseline of knowledge about program implementation and delivery, upon which further research can improve strategies for engaging diverse populations including racial/ethnic minorities.

The majority of the included studies made use of convenience sampling and did not report intentional strategies for achieving racially/ethnically diverse samples. Future studies seeking to establish effectiveness in minority populations and expand generalizability should use formative research to identify or map spaces where members of diverse populations meeting eligibility criteria (e.g., baseline risk factor) congregate. These spaces can include community centers, commercial/retail establishments, health or social service organizations, minority-serving institutions such as schools and/or churches (Pyatak et al., 2013). Specific online or social network sites that reach specific audiences (e.g., Black or African American men, Hispanic women, etc.) can also be beneficial for disseminating information about $\mathrm{MBI}$ research or programs. It may also be useful to establish relationships between $\mathrm{MBI}$ research programs and other health-promotion initiatives for racial/ethnic minority populations, in order to convey authentic interest in expanding the reach and diversifying the user population for $\mathrm{MBI}$ research and programs. Future studies should seek to tailor recruitment to increase inclusion of racial and ethnic minority groups in general, males, low-income minorities, and those with lower levels of education.

Dose, delivery method, and settings present potential targets for intervention tailoring. Implementation details reported in the primary studies show that MBI programs typically involve numerous, lengthy sessions. While settings-including locations, dates, and times-were generally found acceptable among intervention completers, it should be noted that attrition levels, while not directly examined or reported on in this study, were generally high in most studies. Numerous studies speculate that the reason for high attrition levels could stem from the intensity and commitment required by the interventions. Delivery method-particularly in-person classes or sessions-may pose a barrier if the classes are nonrepresentative/held in noncommunity locations. Exploratory research reports a preference for greater racial representation by Black respondents (Woods-Giscombe \& Gaylord, ), presenting an additional consideration for future studies. Given the intersectional nature of many health disparities (Jackson et al., 2016), we believe future studies should also account for SES when considering dosage, locations, and fixed times or days. For example, minority populations often report lower education and income at disparate levels relative to their White, non-Hispanic counterparts (U.S. Census Bureau, 2019). Likewise, two included studies focused on low-SES smokers indicated that some participants "worked odd hours" and that it was necessary to allow them to decline participation if they could not attend all sessions (Davis et al., 2014a; 2014b). This factor has the potential to bias study results in favor of participants with the ability to attend sessions. While the racial/ethnic composition of these participants is not clear, the presence of work/time constraints may point to a potential barrier to engagement among some low- 
SES participants and may warrant further exploration in future research. Similar time conflicts were reported in a study with of Black participants, though some respondents sought additional in-person interactions in this study (Woods-Giscombe \& Gaylord, 2019).

Staff characteristics-in this case, facilitator characteristics-were not described by any studies included in this review. Staff characteristics refer to demographic characteristics such as age and racial/ethnic identity. Non-representative staff characteristics have the potential to act as a barrier to engagement, as minority subjects report (Woods-Giscombe \& Gaylord, 2014). Members of racial/ethnic minority groups are less likely to find representation of other members of their community in mindfulness practice (Cramer et al., 2016) and are more likely to respond to a MBI program facilitator with whom they can identify or whom they feel represents their community (Spears et al., 2017; Watson-Singleton et al., 2019; Mier et al., 2010). A recent qualitative study examining the perceived cultural relevance of MBI by Black Americans reports that respondents would be more likely to interact with and benefit from an instructor who was also Black (Woods-Giscombe \& Gaylord, 2014). The potential of a group's perceptions of their instructor to influence study outcomes was demonstrated in one of the included studies (Daubenmier et al., 2016), in which intervention group participants' weight loss significantly correlated with how helpful they perceived their instructor to be. This finding suggests that results may be instructor-dependent and may be especially relevant for underrepresented minorities who are less likely to identify and/or engage with their instructor. These findings highlight the importance of reporting and evaluating staff characteristics in future research. Future studies should seek to employ interventionists matching the general racial or ethnic characteristics of the participant pool.

In addition to the findings reported here, prior knowledge, beliefs, and social norms about mindfulness/meditation may drive participant engagement and outcomes, as supported by behavior change theories (Bandura, 1991; Ajzen, 1991). The need for considering prior knowledge, beliefs, and social norms about mindfulness in minority groups is also consistent with literature on tailoring interventions to minorities (Spears et al., 2017; Watson-Singleton et al., 2019; Mier et al., 2010). While some studies described explicit exclusion for either mindfulness training or practice (see Results), the potential effects of prior knowledge of, interest in, or experience with mindfulness or meditation remains unclear across all studies. Several studies included in this review highlight these gaps in understanding. In the 2017 study by Ingraham and colleagues, some participants appear to have had an established prior practice, and felt the intervention was too basic for their needs. These findings support the need to understand the perceived cultural relevance of these interventions in underserved populations.

We also propose that app-based interventions may present a way to bypass some of the potential barriers presented by this study, namely the ability to choose a representative instructor, times, dates, 
durations, and locations and needed. In this way, app-based interventions may provide alternate practice opportunities such that more potential participants are targeted. App-based interventions also have the potential to be provided at low or no cost to participants, easy to use, and may provide ease of dissemination (Abroms et al., 2013; Garrison et al., 2020).

In our literature review, we found that MBI may be effective for cardiovascular disease risk outcomes. However, our findings regarding the current limitations in reported studies highlight significant gaps in the literature, leaving the potential efficacy of $\mathrm{MBI}$ in minority communities in question. Our findings highlight several potential targets for tailoring mindfulness-based interventions to cardiovascular risk disparities in racial/ethnic minorities in the US.

This study presents several limitations. As with all systematic reviews, this study may have missed identification of studies meeting eligibility criteria. This study was also limited to articles available in or translated to the English language. The inclusion of a meta-analysis was not possible given the heterogeneity in study designs and outcomes measured. However, as stated, this review did not aim to assess efficacy across studies and thus meta-analysis was not germane to our objectives. The risk factors presented here were researched independent of their role in cardiovascular-specific risk or disease, and this paper does not explore the potential interactions between these (e.g. diet and diabetes, exercise and diabetes, or diabetes and CVD). This study did not examine attrition rates-which were generally high across studies-nor reasons for attrition. This information should be examined in more depth in future scholarship.

\section{Conclusion}

This study outlines several potential targets for future research. As all included studies indicate promise for these interventions, there is cause to believe that MBI could be of benefit to racial/ethnic minority groups at risk for cardiovascular disease, perhaps as a complement to standard forms of treatment. Further research is needed to explore acceptability, feasibility, and effectiveness in racial/ethnic minority populations, and to identify strategies to facilitate awareness, relevance, uptake, and engagement of racial/ethnic minorities in MBI programs and research.

\section{References}

Abroms LC, Lee Westmaas J, Bontemps-Jones J, Ramani R, Mellerson J. A content analysis of popular smartphone apps for smoking cessation. Am J Prev Med. 2013;45(6):732-736. 
Ajzen, I. (1991). The theory of planned behavior. Organizational Behavior and Human Decision Processes, 50(2), 179-211. https://doi.org/10.1016/0749-5978(91)90020-T

Arch, J. J., Brown, K. W., Goodman, R. J., Della Porta, M. D., Kiken, L. G., \& Tillman, S. (2016). Enjoying food without caloric cost: The impact of brief mindfulness on laboratory eating outcomes. Behaviour Research and Therapy, 79, 23-34. https://doi.org/10.1016/j.brat.2016.02.002

Bandura, A. (1991). Social cognitive theory of self-regulation. Organizational Behavior and Human Decision Processes, 50(2), 248-287. https://doi.org/10.1016/0749-5978(91)90022-L

Bishop, S. R., Lau, M., Shapiro, S., Carlson, L., Anderson, N. D., Carmody, J., Segal, Z. V., Abbey, S., Speca, M., Velting, D., \& Devins, G. (2006). Mindfulness: A Proposed Operational Definition. Clinical Psychology: Science and Practice, 11(3), 230-241. https://doi.org/10.1093/clipsy.bph077

Brewer, J. A., Mallik, S., Babuscio, T. A., Nich, C., Johnson, H. E., Deleone, C. M., Minnix-Cotton, C. A., Byrne, S. A., Kober, H., Weinstein, A. J., Carroll, K. M., \& Rounsaville, B. J. (2011). Mindfulness training for smoking cessation: Results from a randomized controlled trial. Drug and Alcohol Dependence, 119(1-2), 72-80. https://doi.org/10.1016/j.drugalcdep.2011.05.027

Carmody, J. F., Olendzki, B. C., Merriam, P. A., Liu, Q., Qiao, Y., \& Ma, Y. (2012). A Novel Measure of Dietary Change in a Prostate Cancer Dietary Program Incorporating Mindfulness Training. Journal of the Academy of Nutrition and Dietetics, 112(11), 1822-1827. https://doi.org/10.1016/j.jand.2012.06.008

Carpenter, K. M., Vickerman, K. A., Salmon, E. E., Javitz, H. S., Epel, E. S., \& Lovejoy, J. C. (2019). A Randomized Pilot Study of a Phone-Based Mindfulness and Weight Loss Program. Behavioral Medicine, 45(4), 271-281. https://doi.org/10.1080/08964289.2017.1384359

Centers for Disease Control and Prevention. Heart disease facts. 2016. Available at: http://www.cdc.gov/heartdisease/facts.htm 
Chacko, S. A., Yeh, G. Y., Davis, R. B., \& Wee, C. C. (2016). A mindfulness-based intervention to control weight after bariatric surgery: Preliminary results from a randomized controlled pilot trial. Complementary Therapies in Medicine, 28, 13-21. https://doi.org/10.1016/j.ctim.2016.07.001

Chiesa, A., \& Serretti, A. (2009). Mindfulness-Based Stress Reduction for Stress Management in Healthy People: A Review and Meta-Analysis. The Journal of Alternative and Complementary Medicine, 15(5), 593-600. https://doi.org/10.1089/acm.2008.0495

Corsica, J., Hood, M. M., Katterman, S., Kleinman, B., \& Ivan, I. (2014). Development of a novel mindfulness and cognitive behavioral intervention for stress-eating: A comparative pilot study. Eating Behaviors, 15(4), 694-699. https://doi.org/10.1016/j.eatbeh.2014.08.002

Cramer, H., Hall, H., Leach, M., Frawley, J., Zhang, Y., Leung, B., Adams, J., \& Lauche, R. (2016). Prevalence, patterns, and predictors of meditation use among US adults: A nationally representative survey. Scientific Reports, 6(1), 36760. https://doi.org/10.1038/srep36760

Crane, R. S., Brewer, J., Feldman, C., Kabat-Zinn, J., Santorelli, S., Williams, J. M. G., \& Kuyken, W. (2017). What defines mindfulness-based programs? The warp and the weft. Psychological Medicine, 47(6), 990999. https://doi.org/10.1017/S0033291716003317

Daubenmier, J., Moran, P. J., Kristeller, J., Acree, M., Bacchetti, P., Kemeny, M. E., Dallman, M., Lustig, R. H., Grunfeld, C., Nixon, D. F., Milush, J. M., Goldman, V., Laraia, B., Laugero, K. D., Woodhouse, L., Epel, E. S., \& Hecht, F. M. (2016). Effects of a mindfulness-based weight loss intervention in adults with obesity: A randomized clinical trial: Mindfulness-Based Weight Loss for Obesity. Obesity, 24(4), 794-804. https://doi.org/10.1002/oby.21396

Daubenmier, J., Kristeller, J., Hecht, F. M., Maninger, N., Kuwata, M., Jhaveri, K., Lustig, R. H., Kemeny, M., Karan, L., \& Epel, E. (2011). Mindfulness Intervention for Stress Eating to Reduce Cortisol and Abdominal Fat among Overweight and Obese Women: An Exploratory Randomized Controlled Study. Journal of Obesity, 2011, 1-13. https://doi.org/10.1155/2011/651936 
Davis, A. M., Vinci, L. M., Okwuosa, T. M., Chase, A. R., \& Huang, E. S. (2007). Cardiovascular Health Disparities. Medical Care Research and Review, 64(5_suppl), 29S-100S. https://doi.org/10.1177/1077558707305416

Davis, J. M., Mills, D. M., Stankevitz, K. A., Manley, A. R., Majeskie, M. R., \& Smith, S. S. (2013). Pilot randomized trial on mindfulness training for smokers in young adult binge drinkers. BMC Complementary and Alternative Medicine, 13(1), 215. https://doi.org/10.1186/1472-6882-13-215

Davis, J. M., Goldberg, S. B., Anderson, M. C., Manley, A. R., Smith, S. S., \& Baker, T. B. (2014a). Randomized Trial on Mindfulness Training for Smokers Targeted to a Disadvantaged Population. Substance Use \& Misuse, 49(5), 571-585. https://doi.org/10.3109/10826084.2013.770025

Davis, J. M., Manley, A. R., Goldberg, S. B., Smith, S. S., \& Jorenby, D. E. (2014b). Randomized trial comparing mindfulness training for smokers to a matched control. Journal of Substance Abuse Treatment, 47(3), 213-221. https://doi.org/10.1016/j.jsat.2014.04.005

Eichel, K., Gawande, R., Acabchuk, R.L. et al. A Retrospective Systematic Review of Diversity Variables in Mindfulness Research, 2000-2016. Mindfulness 12, 2573-2592 (2021).

https://doi.org/10.1007/s12671-021-01715-4

Garrison KA, O'Malley SS, Brewer JA, Potenza MN. Mobile applications for mindfulness training in the treatment of substance use disorders. In: Potenza MN, Faust K, Faust D, eds. The Oxford Handbook of Digital Technologies and Mental Health. Oxford, UK: Oxford University Press; 2020.

Garrison, K. A., Pal, P., O’Malley, S. S., Pittman, B. P., Gueorguieva, R., Rojiani, R., Scheinost, D., Dallery, J., \& Brewer, J. A. (2020). Craving to Quit: A Randomized Controlled Trial of Smartphone App-Based Mindfulness Training for Smoking Cessation. Nicotine \& Tobacco Research, 22(3), 324-331. https://doi.org/10.1093/ntr/nty126

Gillman, A. S., \& Bryan, A. D. (2020). Mindfulness Versus Distraction to Improve Affective Response and Promote Cardiovascular Exercise Behavior. Annals of Behavioral Medicine, 54(6), 423-435. 
Graham, G. (2014). Population-based approaches to understanding disparities in cardiovascular disease risk in the United States. International Journal of General Medicine, 393.

https://doi.org/10.2147/IJGM.S65528

Graham, G. (2015). Disparities in Cardiovascular Disease Risk in the United States. Current Cardiology Reviews, 11(3), 238-245. https://doi.org/10.2174/1573403X11666141122220003

Hölzel, B. K., Lazar, S. W., Gard, T., Schuman-Olivier, Z., Vago, D. R., \& Ott, U. (2011). How Does Mindfulness Meditation Work? Proposing Mechanisms of Action From a Conceptual and Neural Perspective. Perspectives on Psychological Science, 6(6), 537-559. https://doi.org/10.1177/1745691611419671

Ingraham, N., Harbatkin, D., Lorvick, J., Plumb, M., \& Minnis, A. M. (2017). Women's Health and Mindfulness (WHAM): A Randomized Intervention Among Older Lesbian/Bisexual Women. Health Promotion Practice, 18(3), 348-357. https://doi.org/10.1177/1524839916670874

Jackson, J. W., Williams, D. R., \& VanderWeele, T. J. (2016). Disparities at the intersection of marginalized groups. Social Psychiatry and Psychiatric Epidemiology, 51(10), 1349-1359. https://doi.org/10.1007/s00127-016-1276-6

Janes, A. C., Datko, M., Roy, A., Barton, B., Druker, S., Neal, C., Ohashi, K., Benoit, H., van Lutterveld, R., \& Brewer, J. A. (2019). Quitting starts in the brain: A randomized controlled trial of app-based mindfulness shows decreases in neural responses to smoking cues that predict reductions in smoking. Neuropsychopharmacology, 44(9), 1631-1638. https://doi.org/10.1038/s41386-019-0403-y

Kabat-Zinn, J. (1982). An outpatient program in behavioral medicine for chronic pain patients based on the practice of mindfulness meditation: Theoretical considerations and preliminary results. General Hospital Psychiatry, 4(1), 33-47. https://doi.org/10.1016/0163-8343(82)90026-3 
Kabat-Zinn, J. (2003). Mindfulness-Based Interventions in Context: Past, Present, and Future. Clinical Psychology: Science and Practice, 10(2), 144-156. https://doi.org/10.1093/clipsy.bpg016

Khoury, B., Lecomte, T., Fortin, G., Masse, M., Therien, P., Bouchard, V., Chapleau, M.-A., Paquin, K., \& Hofmann, S. G. (2013). Mindfulness-based therapy: A comprehensive meta-analysis. Clinical Psychology Review, 33(6), 763-771. https://doi.org/10.1016/j.cpr.2013.05.005

Kochanek KD, Murphy SL, Xu JQ, Tejada-Vera B. Deaths: Final Data for 2014. National Vital Statistics Reports, 2016; vol 65: no 4. Hyattsville, MD: National Center for Health Statistics.

Kurian, A. K., \& Cardarelli, K. M. (2007). Racial and ethnic differences in cardiovascular disease risk factors: a systematic review. Ethnicity and Disease, 17(1), 143.

Lackland, D. T. (2014). Racial Differences in Hypertension: Implications for High Blood Pressure Management. The American Journal of the Medical Sciences, 348(2), 135-138. https://doi.org/10.1097/MAJ.0000000000000308

Levine, G. N., Lange, R. A., Bairey-Merz, C. N., Davidson, R. J., Jamerson, K., Mehta, P. K., Michos, E. D., Norris, K., Ray, I. B., Saban, K. L., Shah, T., Stein, R., Smith, S. C., \& the American Heart Association Council on Clinical Cardiology; Council on Cardiovascular and Stroke Nursing; and Council on Hypertension. (2017). Meditation and Cardiovascular Risk Reduction: A Scientific Statement From the American Heart Association. Journal of the American Heart Association, 6(10).

https://doi.org/10.1161/JAHA.117.002218

Lotfalian, S., Spears, C. A., \& Juliano, L. M. (2020). The effects of mindfulness-based yogic breathing on craving, affect, and smoking behavior. Psychology of Addictive Behaviors, 34(2), 351-359. https://doi.org/10.1037/adb0000536 
Loucks, E. B., Schuman-Olivier, Z., Britton, W. B., Fresco, D. M., Desbordes, G., Brewer, J. A., \& Fulwiler, C. (2015a). Mindfulness and Cardiovascular Disease Risk: State of the Evidence, Plausible Mechanisms, and Theoretical Framework. Current Cardiology Reports, 17(12), 112. https://doi.org/10.1007/s11886015-0668-7

Macinko, J., \& Upchurch, D. M. (2019). Factors Associated with the Use of Meditation, U.S. Adults 2017. The Journal of Alternative and Complementary Medicine, 25(9), 920-927. https://doi.org/10.1089/acm.2019.0206

Mensah, G. A., Mokdad, A. H., Ford, E. S., Greenlund, K. J., \& Croft, J. B. (2005). State of Disparities in Cardiovascular Health in the United States. Circulation, 111(10), 1233-1241.

https://doi.org/10.1161/01.CIR.0000158136.76824.04

Mier, N., Ory, M. G., Toobert, D. J., Smith, M. L., Osuna, D., McKay, J. R., Villarreal, E. K., DiClemente, R. J., \& Rimer, B. K. (2010). A qualitative case study examining intervention tailoring for minorities. American Journal of Health Behavior, 34(6), 822-832. PMID: 20604705

Miller, C. K., Kristeller, J. L., Headings, A., Nagaraja, H., \& Miser, W. F. (2012). Comparative Effectiveness of a Mindful Eating Intervention to a Diabetes Self-Management Intervention among Adults with Type 2 Diabetes: A Pilot Study. Journal of the Academy of Nutrition and Dietetics, 112(11), 1835-1842. https://doi.org/10.1016/j.jand.2012.07.036

Miller, C. K., Kristeller, J. L., Headings, A., \& Nagaraja, H. (2014). Comparison of a Mindful Eating Intervention to a Diabetes Self-Management Intervention Among Adults With Type 2 Diabetes: A Randomized Controlled Trial. Health Education \& Behavior, 41(2), 145-154.

https://doi.org/10.1177/1090198113493092

Minami, H., Nahvi, S., Arnsten, J. H., Brinkman, H. R., Rivera-Mindt, M., Wetter, D. W., Bloom, E. L., Price, L. H., Richman, E. K., Betzler, T. F., Stockmal, C., Donnelly, R., McClain, L. M., Kennedy, K. A., Vieira, C., Fine, M., McCarthy, D. E., Thomas, J. G., Hecht, J., \& Brown, R. A. (2021). A pilot randomized controlled trial of smartphone-assisted mindfulness-based intervention with contingency management for smokers with mood disorders. Experimental and Clinical Psychopharmacology. https://doi.org/10.1037/pha0000506 
Montgomery, P., Underhill, K., Gardner, F., Operario, D., \& Mayo-Wilson, E. (2013). The Oxford Implementation Index: A new tool for incorporating implementation data into systematic reviews and meta-analyses. Journal of Clinical Epidemiology, 66(8), 874-882.

https://doi.org/10.1016/j.jclinepi.2013.03.006

Muncan, B. (2018). Cardiovascular disease in racial/ethnic minority populations: illness burden and overview of community-based interventions. Public health reviews, 39(1), 1-11.

National Center for Chronic Disease Prevention and Health Promotion (US) Office on Smoking and Health. The Health Consequences of Smoking-50 Years of Progress: A Report of the Surgeon General. Atlanta (GA): Centers for Disease Control and Prevention (US); 2014. Available from: https://www.ncbi.nlm.nih.gov/books/NBK179276/

Olano, H. A., Kachan, D., Tannenbaum, S. L., Mehta, A., Annane, D., \& Lee, D. J. (2015). Engagement in Mindfulness Practices by U.S. Adults: Sociodemographic Barriers. The Journal of Alternative and Complementary Medicine, 21(2), 100-102 https://doi.org/10.1089/acm.2014.0269

Pyatak, E. A., Blanche, E. I., Garber, S. L., Diaz, J., Blanchard, J., Florindez, L., \& Clark, F. A. (2013). Conducting Intervention Research Among Underserved Populations: Lessons Learned and Recommendations for Researchers. Archives of Physical Medicine and Rehabilitation, 94(6), 1190-1198. https://doi.org/10.1016/j.apmr.2012.12.009

Raja-Khan, N., Agito, K., Shah, J., Stetter, C. M., Gustafson, T. S., Socolow, H., Kunselman, A. R., Reibel, D. K., \& Legro, R. S. (2017). Mindfulness-Based Stress Reduction in Women with Overweight or Obesity: A Randomized Clinical Trial: MBSR in Women with Overweight or Obesity. Obesity, 25(8), 1349-1359. https://doi.org/10.1002/oby.21910

Ruscio, A. C., Muench, C., Brede, E., \& Waters, A. J. (2015). Effect of Brief Mindfulness Practice on SelfReported Affect, Craving, and Smoking: A Pilot Randomized Controlled Trial Using Ecological Momentary Assessment. Nicotine \& Tobacco Research, ntv074. https://doi.org/10.1093/ntr/ntv074 
Sala, M., Geary, B., \& Baldwin, A. S. (2021). A Mindfulness-Based Physical Activity Intervention: A Randomized Pilot Study. Psychosomatic Medicine, 83(6), 615-623.

https://doi.org/10.1097/PSY.0000000000000885

Scott-Sheldon, L. A. J., Gathright, E. C., Donahue, M. L., Balletto, B., Feulner, M. M., DeCosta, J., Cruess, D. G., Wing, R. R., Carey, M. P., \& Salmoirago-Blotcher, E. (2020). Mindfulness-Based Interventions for Adults with Cardiovascular Disease: A Systematic Review and Meta-Analysis. Annals of Behavioral Medicine, 54(1), 67-73. https://doi.org/10.1093/abm/kaz020

Singh, N. N., Lancioni, G. E., Winton, A. S. W., Karazsia, B. T., Singh, A. D. A., Singh, A. N. A., \& Singh, J. (2013). A Mindfulness-Based Smoking Cessation Program for Individuals with Mild Intellectual Disability. Mindfulness, 4(2), 148-157. https://doi.org/10.1007/s12671-012-0148-8

Smith, B. W., Shelley, B. M., Sloan, A. L., Colleran, K., \& Erickson, K. (2018). A Preliminary Randomized Controlled Trial of a Mindful Eating Intervention for Post-menopausal Obese Women. Mindfulness, 9(3), 836-849. https://doi.org/10.1007/s12671-017-0824-9

Smith, S. C., Clark, L. T., Cooper, R. S., Daniels, S. R., Kumanyika, S. K., Ofili, E., Quinones, M. A., Sanchez, E. J., Saunders, E., \& Tiukinhoy, S. D. (2005). Discovering the Full Spectrum of Cardiovascular Disease: Minority Health Summit 2003: Report of the Obesity, Metabolic Syndrome, and Hypertension Writing Group. Circulation, 111(10). https://doi.org/10.1161/01.CIR.0000157743.54710.04

Spadaro, K. C., Davis, K. K., Sereika, S. M., Gibbs, B. B., Jakicic, J. M., \& Cohen, S. M. (2018). Effect of mindfulness meditation on short-term weight loss and eating behaviors in overweight and obese adults: A randomized controlled trial. Journal of Complementary and Integrative Medicine, 15(2). https://doi.org/10.1515/jcim-2016-0048

Spears, C. A., Houchins, S. C., Bamatter, W. P., Barrueco, S., Hoover, D. S., \& Perskaudas, R. (2017). Perceptions of Mindfulness in a Low-Income, Primarily African American Treatment-Seeking Sample. Mindfulness, 8(6), 1532-1543. https://doi.org/10.1007/s12671-017-0720-3 
Tang, Y.-Y., Tang, R., \& Posner, M. I. (2013). Brief meditation training induces smoking reduction. Proceedings of the National Academy of Sciences, 110(34), 13971-13975.

https://doi.org/10.1073/pnas.1311887110

Tang, Y.-Y., Hölzel, B. K., \& Posner, M. I. (2015). The neuroscience of mindfulness meditation. Nature Reviews Neuroscience, 16(4), 213-225. https://doi.org/10.1038/nrn3916

Timmerman, G. M., \& Brown, A. (2012). The Effect of a Mindful Restaurant Eating Intervention on Weight Management in Women. Journal of Nutrition Education and Behavior, 44(1), 22-28. https://doi.org/10.1016/j.jneb.2011.03.143

U.S. Census Bureau (2019) Income and Poverty in the United States: 2019. Retrieved from https://www2.census.gov/programs-surveys/demo/tables/p60/270/

Vidrine, J. I., Spears, C. A., Heppner, W. L., Reitzel, L. R., Marcus, M. T., Cinciripini, P. M., Waters, A. J., Li, Y., Nguyen, N. T. T., Cao, Y., Tindle, H. A., Fine, M., Safranek, L. V., \& Wetter, D. W. (2016). Efficacy of mindfulness-based addiction treatment (MBAT) for smoking cessation and lapse recovery: A randomized clinical trial. Journal of Consulting and Clinical Psychology, 84(9), 824-838. https://doi.org/10.1037/ccp0000117

Waldron, E. M., Hong, S., Moskowitz, J. T., \& Burnett-Zeigler, I. (2018). A Systematic Review of the Demographic Characteristics of Participants in US-Based Randomized Controlled Trials of MindfulnessBased Interventions. Mindfulness, 9(6), 1671-1692. https://doi.org/10.1007/s12671-018-0920-5

Walton-Moss, B., Samuel, L., Nguyen, T. H., Commodore-Mensah, Y., Hayat, M. J., \& Szanton, S. L. (2014). Community-Based Cardiovascular Health Interventions in Vulnerable Populations: A Systematic Review. Journal of Cardiovascular Nursing, 29(4), 293-307. https://doi.org/10.1097/JCN.0b013e31828e2995 
Watson-Singleton, N. N., Black, A. R., \& Spivey, B. N. (2019). Recommendations for a culturally-responsive mindfulness-based intervention for African Americans. Complementary Therapies in Clinical Practice, 34, 132-138. https://doi.org/10.1016/j.ctcp.2018.11.013

Woods-Giscombe, C. L., \& Gaylord, S. A. (2014). The Cultural Relevance of Mindfulness Meditation as a Health Intervention for African Americans: Implications for Reducing Stress-Related Health Disparities. Journal of Holistic Nursing, 32(3), 147-160. https://doi.org/10.1177/0898010113519010

Woods-Giscombe, C. L., Gaylord, S. A., Li, Y., Brintz, C. E., Bangdiwala, S. I., Buse, J. B., Mann, J. D., Lynch, C., Phillips, P., Smith, S., Leniek, K., Young, L., Al-Barwani, S., Yoo, J., \& Faurot, K. (2019). A Mixed-Methods, Randomized Clinical Trial to Examine Feasibility of a Mindfulness-Based Stress Management and Diabetes Risk Reduction Intervention for African Americans with Prediabetes. Evidence-Based Complementary and Alternative Medicine, 2019, 1-16. https://doi.org/10.1155/2019/3962623

Wright, K. D., Klatt, M. D., Adams, I. R., Nguyen, C. M., Mion, L. C., Tan, A., Monroe, T. B., Rose, K. M., \& Scharre, D. W. (2021). Mindfulness in Motion and Dietary Approaches to Stop Hypertension (DASH) in Hypertensive African Americans. Journal of the American Geriatrics Society, 69(3), 773-778. https://doi.org/10.1111/jgs.16947

\section{Figures}



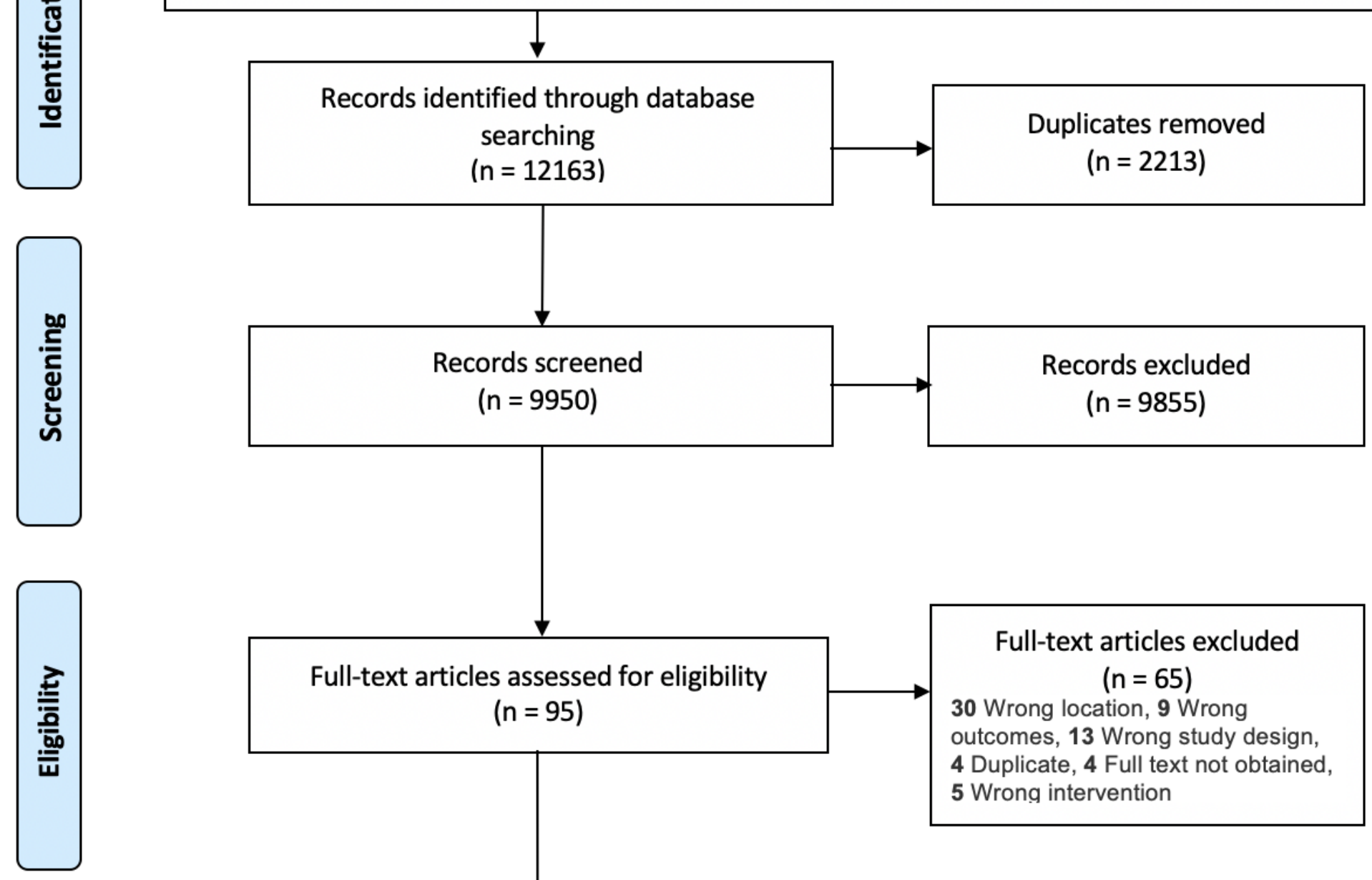

Figure 1

PRISMA Flow Diagram

\section{Supplementary Files}

This is a list of supplementary files associated with this preprint. Click to download.

- Tables23appendixandsupplemental.pdf 